\title{
DESEMPENHO PONDERAL E REPRODUTIVO NO PERÍODO DAS ÁGUAS DE NOVILHAS PRIMÍPARAS NELORE COM COMPLEMENTO PROTEICO PRÉVIO NA SECA
}

\author{
PONDERAL AND REPRODUCTIVE PERFORMANCE DURING RAIN \\ SEASON OF NELLORE PRIMIPAROUS HEIFERS PREVIOUSLY \\ SUPPLEMENTED WITH PROTEIN IN DRY SEASON
}

\author{
Ana Paula Carneiro Nogueira ${ }^{*}$ \\ Paula Batista de Alvarenga ${ }^{1}$ \\ Isabel Cristina Ferreira ${ }^{2}$ \\ Maisa Paschoal Rios ${ }^{1}$ \\ Cecilia Rodrigues Silva ${ }^{1}$ \\ 1Universidade Federal de Uberlândia, Faculdade de Medicina Veterinária, Uberlândia, MG, Brasil
Embrapa Cerrados, Brasília, DF, Brasil.
"Autor para correspondência - apnogueira_17@hotmail.com
}

\section{Resumo}

Objetivou-se avaliar, no período chuvoso, o efeito da complementação no período seco com proteinado, em novilhas primíparas Nelore por meio de parâmetros produtivos e reprodutivos. Para isto, foram utilizadas 39 fêmeas bovinas entre 24-36 meses, em pastagens de Brachiaria brizantha e Brachiaria decumbens por 205 dias, pesadas a cada 28 dias, após jejum de 12 horas. O delineamento experimental foi em parcelas subdivididas, sendo os dois tratamentos distribuídos em duas parcelas, os seis períodos na sub parcela e os animais foram a repetição. As variáveis analisadas foram peso, altura de garupa, escore corporal, ganho em peso médio diário e crescimento médio mensal com valores de, respectivamente, $318,5 \mathrm{Kg}, 142 \mathrm{~cm}, 3,24,0,580 \mathrm{Kg}$ e 2,55 cm para os animais previamente complementados e $309,6 \mathrm{Kg}, 141 \mathrm{~cm}, 3,23,0,584 \mathrm{Kg}$ e 2,29 cm para os animais não complementados, não apresentando diferenças entre os dois grupos experimentais. A taxa de prenhez dos animais complementados foi de $57 \%$ e não diferiu dos não complementados (45\%). A taxa de parição foi de $100 \%$ nos dois grupos experimentais. No período chuvoso após a complementação, as novilhas que não receberam complementação prévia no período seco do ano apresentaram desempenho ponderal e reprodutivo semelhante ao das complementadas.

Palavras-chave: bovinos de corte; complementação proteica; realimentação; reprodução; restrição alimentar.

\begin{abstract}
The objective of this study was to evaluate, in rainy season, the effect of protein complementation during dry season on Nellore primiparous heifers. We used 39 primiparous heifers, with an average age of 24-36 months, reared on Brachiaria decumbens and Brachiaria Brizantha pasture, for 205
\end{abstract}


days. The animals were weighed every 28 days, after fasting for 12 hours. The experimental design was a split plot, the two treatments were distributed in two installments, the six periods in subplots and the animals were the replications. The following variables were analyzed: weight, hip height, body condition score, average daily weight gain and average monthly growth, presenting the respective values of $318.5 \mathrm{~kg}, 142 \mathrm{~cm}, 3.24,0.580 \mathrm{~kg}$ and $2.55 \mathrm{~cm}$ respectively for previously supplemented animals, and $309.6 \mathrm{~kg}, 141 \mathrm{~cm}, 3.23,0.584$ and $2.29 \mathrm{~kg} \mathrm{~cm}$ for non-supplemented animals. There were no significant differences between the two experimental groups. Pregnancy rate of supplemented animals was $57 \%$ and it did not differ from non-supplemented animals' rate (45\%). Calving rate was $100 \%$ for both groups. In the rainy season, after supplementation, heifers that did not receive supplementation during the dry period of the previous year had similar reproductive and weight performance as the supplemented ones.

Keywords: beef cattle; dietary restriction; feedback; protein supplementation; reproduction.

Recebido em: 13 maio 2013.

Aceito em: 07 novembro 2014

\section{Introdução}

No Brasil Central Pecuário, bovinos mantidos em pastagens são submetidos a uma estacionalidade distinta na oferta e qualidade de forragem, ficando expostos a essas modificações, caracterizadas por escassez e abundância de forragem no decorrer do ano ${ }^{(1,2)}$, que apresenta uma estação seca, compreendida entre os meses de abril e outubro, e outra chuvosa, de novembro a março.

A base para a alimentação de bovinos de corte no Brasil são as pastagens, que representam a forma mais prática e econômica da nutrição ${ }^{(2)}$. Há, no entanto, a necessidade de se conhecer as respostas dos animais nas duas estações do ano, para promover o planejamento nutricional e reprodutivo do rebanho, uma vez que a sazonalidade na produção de forragem tem se mostrado um desafio à produção animal em pastagem ${ }^{(3)}$.

Um dos pontos que necessita de mais estudos é a composição do crescimento e o ganho de peso dos animais quando têm uma taxa de crescimento limitado, devido à quantidade e qualidade diminuídas de alimento, o que causa um crescimento inferior ao normal e, logo após esse período, recebem alimentos de alta qualidade e em quantidade ilimitadas ${ }^{(4)}$. Os animais que sofrem essa restrição alimentar têm a velocidade de ganho de peso aumentada quando submetidos à reposição de nutrientes, também chamada de realimentação, quando comparados a animais não submetidos a uma restrição alimentar prévia, caracterizando o chamado ganho compensatório ${ }^{(4,5)}$.

Falhas na alimentação de novilhas durante a estação seca podem ser uma das causas do aumento da idade à puberdade, da baixa taxa de prenhez e piores índices de reconcepção quando se tornam primíparas. O peso vivo, ganho de peso nos períodos pré e pós-desmama, a condição corporal dos animais e a idade em que estes alcançam a puberdade são também decisivos na redução da idade ao primeiro acasalamento ${ }^{(6,7)}$.

Novilhas que recebem algum tipo de complemento alimentar na seca apresentam maior desenvolvimento e maiores taxas de prenhez que as não complementadas; entretanto, o desempenho subsequente desses animais no período chuvoso apresenta controvérsias. Cavalvanti Filho et al. ${ }^{(8)}$ disseram não haver diferença no desempenho após complementação, enquanto Semmelmann et al. ${ }^{(9)}$ 
apontaram maior crescimento dos animais não complementados. Não há padronização do tipo de complementação, se energética e/ou proteica ou ambas, e a resposta pode variar em função de diferentes situações experimentais.

A hipótese é de que, considerando as variáveis com maior facilidade de serem medidas, peso, escore de condição corporal e altura de garupa dos animais, o grupo de novilhas não alimentadas com proteinado na seca apresentasse maior ganho de peso e crescimento corporal, porém, com taxas reprodutivas inferiores às alimentadas. Assim sendo, objetivou-se avaliar, no período chuvoso, o efeito da complementação na seca com proteinado, em novilhas primíparas Nelore por meio de parâmetros produtivos e reprodutivos.

\section{Material e Métodos}

Neste experimento, utilizaram-se 39 fêmeas Nelore em fase de recria, com idade média de 24-36 meses, peso médio inicial de $262 \mathrm{~kg} \pm 26 \mathrm{~kg}$, mantidas em pastagens de Brachiaria brizantha e Brachiaria decumbens, na Fazenda Experimental do Capim Branco da Universidade Federal de Uberlândia (UFU) por 205 dias, no período de 29 de novembro de 2010 a 22 de junho de 2011.

Previamente ao presente trabalho, no período seco (maio a outubro de 2010), as 39 novilhas foram divididas em dois grupos, um composto por 20 animais que receberam complementação proteica e outro grupo formado por 19 animais controle, que não receberam nenhum tipo de complementação. O complemento proteico utilizado era composto de $37 \%$ de proteína bruta e $10 \%$ de ureia, tendo em sua composição o que segue: cloreto de sódio; enxofre ventilado; farelo de soja; fosfato bicálcico; iodato de cálcio; milho integral moído; óxido de magnésio; óxido de zinco; selenito de sódio; sulfato de cobalto; sulfato de cobre; sulfato de ferro; sulfato de manganês e ureia pecuária.

Em novembro de 2010, as fêmeas foram agrupadas em um só pasto e passaram a fazer parte do manejo normal da fazenda, sendo tratadas contra endoparasitos e vacinadas contra febre aftosa e raiva em maio. A cada 28 dias, após jejum de 12 horas, os animais eram pesados, por meio de balança devidamente aferida, medidos na altura da garupa, com régua graduada em centímetros e avaliados quanto ao escore de condição corporal de 1 a 5, sendo (1) animais muito magros e (5) animais muito obesos, conforme utilizado por Ferreira et al. ${ }^{(10)}$; além disso, houve coleta de amostras de forragens. $\mathrm{O}$ método de coleta das pastagens foi o mesmo empregado por Barbero et al. ${ }^{(11)}$. As amostras não foram obtidas no mês de maio por problemas operacionais na fazenda. As análises químicas das pastagens foram realizadas de acordo com o Compêndio Brasileiro de Alimentação Animal ${ }^{(12)}$ no laboratório de nutrição animal da UFU.

Para avaliação da taxa de prenhez, foi realizada palpação retal após a estação de monta, de 63 dias, juntamente com a utilização de ultra-sonografia por via transretal, utilizando-se um aparelho de ultrasom portátil Aloka ${ }^{\circledR}$ SSD-500, para a detecção de concepto e/ou membranas fetais ${ }^{(13)}$. A taxa de natalidade foi determinada dividindo-se o número de animais que pariram pelo número de novilhas expostas à reprodução e a taxa de parição foi obtida pela razão do número de nascimentos pelo número de vacas diagnosticadas prenhas.

A taxa de lotação foi calculada, com o intuito de se obter um bom aproveitamento das pastagens pelos animais. Considerou-se eficiência de pastejo de $50 \%$, obtida pela formula:

$\mathrm{EP}=[\mathrm{DF}(1-\mathrm{P}) / \mathrm{AF}] 100$, em que:

EP é a eficiência de pastejo em porcentagem; 
DF é o desaparecimento de forragem em $\mathrm{kg} \mathrm{ha}^{-1}$;

AF é o acúmulo de forragem, considerando o período pré e pós-medida em $\mathrm{kg} \mathrm{ha}^{-1}$ obtida de gaiolas de exclusão. A taxa de crescimento foi calculada em função dos intervalos das coletas de amostras; em seguida, obteve-se a taxa de lotação instantânea, considerando-se um consumo médio de matéria seca pelas novilhas de aproximadamente $9 \mathrm{Kg} / \mathrm{MS} / \mathrm{animal} / \mathrm{dia}$, valor que foi estimado pela diferença da massa de forragem antes e após pastejo.

A medida da área de pasto foi feita com sistema de posicionamento global (GPS), aparelho que trabalha realizando as medições das coordenadas geográficas, registrando a localização de todas as medições com precisão e permitindo uma correção em tempo real ${ }^{(14)}$.

O delineamento experimental utilizado foi em parcelas subdivididas, sendo os dois tratamentos distribuídos em duas parcelas e os seis períodos na sub-parcela e os animais foram a repetição. As variáveis analisadas foram ganho de peso, ganho médio diário, altura de garupa, escore corporal, taxa de prenhez e taxa de natalidade.

Análises de variância e comparação de médias pelo teste de $\mathrm{F}$ foram efetuadas nas variáveis paramétricas e teste qui-quadrado ou exato de Fisher nas variáveis não paramétricas, com nível de significância de $5 \%$.

A composição química da forragem e a taxa de lotação foram obtidas no decorrer do experimento para caracterizar o sistema de produção.

Todos os procedimentos experimentais realizados com os animais foram previamente aprovados pelo Comitê de Ética na Utilização de Animais (CEUA) da UFU sob processo nº. 011/2011.

\section{Resultados e Discussão}

Os valores obtidos para o peso, altura de garupa, escore de condição corporal, ganho em peso e crescimento médios, nos seis períodos avaliados, não apresentaram diferenças significativas entre os dois grupos experimentais, provavelmente devido ao ganho compensatório apresentado pelos animais não complementados previamente, levando a um "empate" nos ganhos dos dois grupos, o que pode ser evidenciado na Tabela 1.

Tabela 1: Médias e desvios-padrão de diferentes parâmetros no período das águas, para novilhas previamente complementadas e não complementadas no período da seca

\begin{tabular}{lcccc}
\hline \multicolumn{1}{c}{ Variáveis } & Complementadas & $\begin{array}{c}\text { Não } \\
\text { Complementadas }\end{array}$ & C.V $^{\mathbf{1}}$ & $\begin{array}{c}\text { Valor } \\
\text { de p }\end{array}$ \\
\hline Peso médio inicial (Kg) & $270,0 \pm 24,0$ & $255,0 \pm 24,0$ & 9,81 & 0,08 \\
Peso médio do período (Kg) & $318,5 \pm 46,6$ & $309,6 \pm 50,7$ & 9,44 & 0,52 \\
Altura garupa (cm) & $142,0 \pm 3,12$ & $141,0 \pm 3,01$ & 1,98 & 0,28 \\
ECC (1 a 5) & $3,24 \pm 0,42$ & $3,23 \pm 0,41$ & - & 0,91 \\
Peso médio final (Kg) & $397,4 \pm 34,0$ & $385,8 \pm 36,6$ & 9,03 & 0,31 \\
Ganho de peso médio diário (Kg) & $0,580 \pm 0,321$ & $0,584 \pm 0,304$ & 48,66 & 0,77 \\
Crescimento (cm/mês) & $2,55 \pm 1,91$ & $2,29 \pm 1,97$ & 65,94 & 0,25 \\
\hline CV1 ${ }^{1}$ Coeficiente de Variação & & & &
\end{tabular}

Tais resultados concordam com os obtidos por Abouheif et al. ${ }^{(15)}$, que descreveram ausência de diferenças significativas na fase de realimentação para o ganho de peso de cordeiros. Essa resposta 
pode ser atribuída ao crescimento compensatório apresentado nesse período pelos animais não complementados, enquanto o grupo complementado não apresenta tão evidente "fenômeno" que, por sua vez, caracteriza-se pelo fato de permitir que animais alcancem níveis de crescimento similares ao daqueles que tiveram crescimento contínuo ${ }^{(16)}$. Essa restrição se dá devido à baixa concentração de energia metabolizável das forrageiras, à baixa densidade de folhas por unidade de área das pastagens brasileiras e também à grande alteração na disponibilidade de pastagens ${ }^{(17)}$.

Efeitos semelhantes foram descritos por Cavalcanti Filho et al. ${ }^{(8)}$, que utilizaram 18 novilhas 5/8 Holandês/Zebu, com média de 20 meses de idade e $267,33 \mathrm{Kg}$, e não obtiveram efeito significativo entre tratamentos com e sem complementação prévia, quanto ao peso vivo inicial, peso vivo final e o ganho de peso médio diário. Apesar de os resultados dos tratamentos não serem diferentes, esses autores observaram que animais não complementados apresentaram maior ganho de peso médio diário, recuperando o peso perdido durante o período de complementação.

Diferentes respostas foram descritas por Arrigoni et al. ${ }^{(18)}$, que avaliaram a ocorrência de ganho compensatório entre os tratamentos com e sem a restrição alimentar, utilizando 66 bovinos inteiros, de cruzamento Simental x Nelore, com idade entre sete e oito meses e peso médio inicial de $220 \pm 34,03 \mathrm{~kg}$, submetidos a três tipos de dietas distintas (um grupo de animais não foi submetido à restrição alimentar e outros dois grupos receberam dietas com restrição alimentar).

Euclides et al. ${ }^{(19)}$ utilizaram 60 bezerros provenientes de cruzamento Angus e Nelore, com peso médio de $195 \mathrm{Kg}$ e sete meses de idade, que, após a desmama, foram submetidos a tratamentos com e sem complementação durante o período seco do ano. Esses autores encontraram, durante o primeiro período chuvoso após a complementação, ganhos em peso semelhantes para ambos os tratamentos utilizados, demonstrando ausência total de ganho compensatório. Já no segundo período chuvoso, após a complementação dos animais, observou-se que aqueles que passaram pela restrição alimentar apresentaram ganho de peso superiores àqueles que não sofreram restrição, o que foi caracterizado pelos autores como uma compensação parcial, já que mesmo com o ganho de peso superior, esses animais não atingiram peso ao abate à mesma idade dos animais complementados.

A interação do período e do tratamento não foi significativa para todas as variáveis avaliadas; entretanto, o peso, a altura de garupa, o escore de condição corporal, o ganho em peso e o crescimento foram significativos para os diferentes períodos avaliados. A análise foi realizada independente do efeito de tratamento (Tabela 2).

Ao final do período avaliado, as novilhas complementadas e não complementadas apresentaram o pico de ganho em peso no mês de fevereiro $(854 \mathrm{~g} / \mathrm{dia})$, fato ocorrido pela maior oferta de forragem no período, o maior crescimento foi no observado no mês de janeiro e os animais cresceram entre 1,1 e $2,6 \mathrm{~cm} / \mathrm{mês}$.

Ao parto, os dados de peso, altura, peso do bezerro e idade da vaca se apresentaram de acordo com alguns valores de referência (Tabela 3).

A idade média dos animais ao primeiro parto variou de 33,7 a 42,9 meses. Os valores ficaram dentro da média encontrada por Laureano et al. ${ }^{(20)}$, que foi de 35,07 meses obtidos por avaliações em novilhas zebuínas, como também as médias obtidas por Pereira et al. ${ }^{(21)}$, que foram de 35,18 meses. Vieira et al. ${ }^{(22)}$ encontraram valores semelhantes, média de 36,26 meses de idade para a raça Nelore. Matos et al. ${ }^{(23)}$ relataram valores médios de 37 meses. Tanaka et al. ${ }^{(24)}$ relatam médias de 35,08 meses. Esses artigos descreveram registros de vários estudos com animais da raça Nelore no Brasil. A média reportada por Dias et al. ${ }^{(25)}$, que estudaram 6.000 novilhas Nelore, variou de 34,4 a 35 meses de idade ao primeiro parto. Os sistemas de produção mais tradicionais até 2006 relatam que a idade média 
brasileira ao primeiro parto foi de aproximadamente 48 meses $^{(26)}$; portanto, observa-se uma melhoria neste índice nos últimos 10 anos no Brasil.

Tabela 2: Médias e desvios-padrões de diferentes parâmetros nos meses de período chuvoso para novilhas previamente complementadas e não complementadas no período da seca

\begin{tabular}{cccccc}
\hline Meses & Peso(kg) & $\begin{array}{c}\text { Altura de } \\
\text { garupa (cm) }\end{array}$ & $\begin{array}{c}\text { Escore de } \\
\text { Condição } \\
\text { Corporal }\end{array}$ & $\begin{array}{c}\text { Ganho de } \\
\text { peso médio } \\
\text { diário }(\mathbf{k g})\end{array}$ & $\begin{array}{c}\text { Crescimento } \\
\text { (cm/mês) }\end{array}$ \\
\hline Dezembro & $262,5 \pm 26,5 \mathrm{e}$ & $139,4 \pm 3,54 \mathrm{c}$ & $2,8 \pm 0,2 \mathrm{c}$ & $0,528 \pm 0,266 \mathrm{bc}$ & $2,1 \pm 1,7 \mathrm{~b}$ \\
Janeiro & $283,1 \pm 26,6 \mathrm{~d}$ & $140,4 \pm 2,55 \mathrm{cb}$ & $2,9 \pm 0,3 \mathrm{bc}$ & $0,379 \pm 0,373 \mathrm{c}$ & $2,6 \pm 1,6 \mathrm{a}$ \\
Fevereiro & $296,4 \pm 29,1 \mathrm{~d}$ & $142,1 \pm 2,94 \mathrm{ba}$ & $3,1 \pm 0,3 \mathrm{~b}$ & $0,854 \pm 0,420 \mathrm{a}$ & $1,2 \pm 1,5 \mathrm{c}$ \\
Março & $319,8 \pm 30,4 \mathrm{c}$ & $141,5 \pm 2,37 \mathrm{~b}$ & $3,2 \pm 0,3 \mathrm{~b}$ & $0,656 \pm 0,255 \mathrm{~b}$ & $1,1 \pm 1,2 \mathrm{c}$ \\
Abril & $342,0 \pm 31,1 \mathrm{~b}$ & $142 \pm 2,69 \mathrm{ba}$ & $3,6 \pm 0,2 \mathrm{a}$ & $0,516 \pm 0,095 \mathrm{bc}$ & $2,0 \pm 1,4 \mathrm{~b}$ \\
Junho & $380,0 \pm 32,9 \mathrm{a}$ & $143,5 \pm 2,88 \mathrm{a}$ & $3,5 \pm 0,3 \mathrm{a}$ & $0,576 \pm 0,105 \mathrm{~b}$ & $2,1 \pm 1,8 \mathrm{~b}$ \\
\hline
\end{tabular}

${ }^{a}$ médias seguidas de letras distintas na coluna diferem $(\mathrm{p}<0,05)$ pelo teste SNK.

Tabela 3: Médias e Desvio Padrão da idade, altura, peso da vaca ao parto e peso do bezerro ao nascer para animais de grupos previamente complementadas e não complementadas no período da seca

\begin{tabular}{lcc}
\hline Variável & Complementadas & Não complementadas \\
\hline Idade da vaca ao parto (meses) & $38,9 \pm 5,2$ & $39,5 \pm 3,4$ \\
Peso vaca ao parto $(\mathrm{kg})$ & $397,4 \pm 42,8$ & $382,9 \pm 27,5$ \\
Altura da vaca ao parto $(\mathrm{cm})$ & $143,7 \pm 2,8$ & $142,7 \pm 2,7$ \\
Peso bezerro ao nascimento $(\mathrm{kg})$ & $31,4 \pm 4,8$ & $30,4 \pm 4,3$ \\
\hline
\end{tabular}

Rocha e Lobato ${ }^{(27)}$ encontraram resultados inferiores aos obtidos neste estudo; no entanto, tais autores submeteram novilhas Nelores ao acasalamento aos 14 - 15 meses de idade, obtendo dessa forma uma idade ao parto de aproximadamente 24 meses. Para a obtenção desses resultados, os animais foram submetidos a práticas de alimentação e manejos diferenciados, associados à genética animal, à realização da desmama precoce e, assim, a um acasalamento antecipado.

O peso das primíparas ao parto reflete a condição alimentar da vaca durante a gestação, sendo, portanto, uma variável importante para determinar o subsequente desempenho reprodutivo desses $\operatorname{animais}^{(28,29)}$.

O manejo nutricional das primíparas deve ser adequado, de modo que os animais apresentem uma condição corporal favorável, propiciando-lhes o retorno da ciclicidade ovariana. Mesmo sendo uma avaliação subjetiva, o escore de condição corporal (ECC) é um bom indicador das reservas corporais das fêmeas e tanto o ECC muito baixo como muito elevados antes do parto tendem a prolongar o período de anestro no pós-parto e, consequentemente, reduzir as taxas de concepção e prenhez durante a estação de monta seguinte ${ }^{(30)}$.

Freetly et al. ${ }^{(31)}$ observaram que novilhas de primeira cria que passaram por um período de restrição nutricional, realimentadas apenas aos 28 dias após o parto, pariram bezerros mais leves e com menor ganho de peso nos primeiros 28 dias de vida. Resultados diferentes foram encontrados por Freetly et al. ${ }^{(32)}$, pois vacas submetidas a ganhos de peso restritos durante a gestação e que, ao final deste período, passaram por um ganho de peso acelerado, não demonstraram redução na fertilidade nem do peso do bezerro ao nascimento. Concluindo, assim, que uma restrição nutricional e consequente déficit no balanço energético dos animais comprometeu a produção de leite dessas fêmeas e o peso 
dos bezerros ao nascimento, proporcionando uma menor taxa de ganho de peso, sem, contudo comprometer a taxa de prenhez das fêmeas na gestação seguinte ${ }^{(30)}$.

Segundo Soca ${ }^{(29)}$, primíparas que ao parto são submetidas à dieta com baixo nível de nutrientes, principalmente energia, apresentam uma forte queda do peso vivo e têm sua performance reprodutiva comprometida quando adultas. Afirma ainda que, quando há uma forte queda no peso vivo dos animais durante o período pré-parto, o nível de nutrientes no pós-parto torna-se significativamente mais importante em determinar o momento do aparecimento do primeiro cio no pós-parto. Outros autores como Lobato et al. ${ }^{(6)}$, estudaram vacas mestiças primíparas (Tabapuã ou Nelore x Devon) e verificaram que, ao parirem com nível nutricional alto, os animais apresentaram no pós-parto um aumento no índice de prenhez e intervalos de partos inferiores a 365 dias.

Os resultados obtidos demonstram que as primíparas ao parto apresentaram pesos que variaram de 355,4 a 440,2 Kg. Parte dessas médias estão dentro do intervalo relatado por Vieira et al. ${ }^{(22)}$, que descreveram valores de $436 \pm 30,86 \mathrm{Kg}$ para novilhas da raça Nelore antes do parto. Primíparas mais leves ao parto podem interferir negativamente nos índices reprodutivos para a próxima estação de monta, porém isso não foi quantificado no presente experimento.

Quanto à altura de garupa das primíparas no momento do parto, observou-se variação entre 140 e $146,5 \mathrm{~cm}$. Freneau et al. ${ }^{(33)}$ verificaram que novilhas Nelore apresentaram médias de altura de garupa de 141 a $142 \mathrm{~cm}$. Animais com o mesmo peso podem apresentar diferenças de altura de posterior para mais ou para menos, sendo, dessa forma, um indicativo de que apenas a pesagem ou a medida da altura dos animais não seria suficiente para predizer o crescimento/desenvolvimento dos animais. Esses autores recomendam avaliar também o ECC para melhor estimar essas características.

Para Cordova e Ciffoni ${ }^{(34)}$, no que diz respeito à maturidade, a influência do ambiente sobre a altura, que se estabelece mais cedo, é menor que sobre o peso; portanto, é recomendável que se utilize da altura dos animais para se selecionar aqueles mais precoces para características reprodutivas.

A variação de peso ao nascimento das crias de primíparas foi de 26,1 a $36,2 \mathrm{Kg}$, valores considerados dentro da média brasileira para bezerros da raça Nelore, o que pode ser atribuído às condições corporais da mãe durante a gestação bem como à qualidade da pastagem fornecida aos animais, uma vez que a pastagem utilizada foi regularmente corrigida. Pesos dentro desse intervalo foram relatados por Souza et al. ${ }^{(35)}$, que observaram médias de 31,90 \pm 5,10 kg ao nascimento, e por Boligon et al. ${ }^{(36)}$, que encontraram valores de $32 \mathrm{~kg}$ em bezerros da raça Nelore, considerados próximos à média brasileira.

A taxa de prenhez entre os dois grupos de novilhas não apresentou diferença significativa, contrapondo-se à hipótese de que as novilhas não complementadas apresentariam taxas reprodutivas inferiores às das que previamente foram complementadas (Tabela 4).

As taxas de prenhez observadas neste experimento foram de $45 \%$ e $57 \%$ para o grupo não tratado e o tratado, respectivamente. Essas taxas são consideradas baixas para a categoria de novilha quando comparadas aos resultados dos demais autores. Essa baixa resposta pode ser atribuída ao curto período da estação de monta utilizado pela fazenda, no qual foi dada a oportunidade de três ciclos estrais às novilhas. A suplementação de seca e a transição seca-águas podem impulsionar o ganho de peso nessa fase e uniformizá-lo para se obter menor variação de pesos à cobertura no lote e, consequentemente, melhores resultados na taxa de prenhez. 
Tabela 4: Taxas de prenhez de novilhas, natalidade e parição de primíparas previamente complementadas e não complementadas no período seco

\begin{tabular}{lcccc}
\hline Tratamento & Prenha & Não prenha & Natalidade & Parição \\
\hline Não complementada & $9 / 20(45 \%)$ & $11 / 20(55 \%)$ & $9 / 20(45 \%)$ & $9 / 9(100 \%)$ \\
Complementada & $11 / 19(57 \%)$ & $8 / 19(42 \%)$ & $11 / 19(57 \%)$ & $11 / 11(100 \%)$ \\
& Valor de p: 0,5273 & & \\
\hline
\end{tabular}

Resultados semelhantes foram citados por Lobato et al. ${ }^{(6)}$, que, ao estudarem grupos de primíparas Devon recebendo suplemento e grupos de primíparas mantidas apenas em pastagens naturais, não observaram diferenças significativas nas taxas de prenhez entre os dois tratamentos. Esses autores justificaram as taxas de prenhez semelhantes para grupos com e sem suplemento pelo fato de que os diferentes níveis nutricionais nas dietas de ambos os grupos podem não influenciar a fertilidade das vacas, mas, sim, o aumento na produção de leite dos animais.

Lobato et al. ${ }^{(6)}$ encontraram valores altos próximos a 86,4 \% e 95,2\%; no entanto, tais valores foram obtidos apenas para animais mantidos em pastagens melhoradas. Esses autores encontraram ainda valores de $66,7 \%$ para primíparas mantidas em pastagens naturais e $35 \%$ para primíparas mantidas em pastagens naturais e suplementadas com feno. Essa inferioridade nos valores encontrados foi explicada pelos autores pela baixa qualidade do suplemento fornecido aos animais ou ainda pela baixa qualidade das pastagens onde foram mantidos.

Vieira et al. ${ }^{(22)}$ descreveram taxas de $88,4 \%$ de prenhez e justificaram esse aumento na taxa de prenhez de primíparas pelo fato de que as novilhas que apresentaram prenhez eram aproximadamente $9,8 \mathrm{Kg}$ mais pesadas que aquelas novilhas que ficaram vazias. Fujita et al. ${ }^{(37)}$ obtiveram taxas de prenhez de $46,9 \%$ e $48,9 \%$ em novilhas Nelore sincronizadas e inseminadas em tempo fixo com sêmen resfriado e congelado.

A caracterização descritiva da forrageira no período experimental (Tabela 5) indica que os níveis de FDN e FDA mantiveram-se com pequena variação durante o período avaliado, exceto no mês de fevereiro, quando o nível de FDA se aproximou dos níveis de FDN. Isso pode ser explicado pelo fato de que, nesse período, as forrageiras ainda não se encontravam em estado maduro e ainda não haviam estabilizado fisiologicamente seus níveis de FDN e FDA.

As forrageiras, quando maduras, apresentam níveis de FDN e FDA maiores que os de forrageiras em seu estado vegetativo, devido ao acúmulo de MS durante o processo de crescimento da planta forrageira, que é o principal responsável pelo decréscimo na digestibilidade. Isso acontece porque o depósito de MS ocorre principalmente na parede celular, acompanhado pela forte aderência da lignina em meio às fibrilas de hemicelulose e celulose ${ }^{(38)}$.

Os níveis de NDT mantiveram-se com pequenas variações durante todo o período do ano. Já os níveis de MS apresentaram pequenas variações e tiveram uma elevação no mês de junho, devido ao ciclo vegetativo das plantas, pois, após florescimento, segue a senescência e com ausência e/ou baixa de precipitação pluviométrica há diminuição da umidade do solo, o que paralisa o crescimento das plantas e praticamente não há rebrota. 
Tabela 5: Composição química, em \%, das pastagens no período chuvoso utilizadas para novilhas complementadas previamente e não complementadas no período da seca

\begin{tabular}{llllllllll}
\hline & MS & PB & NDT & FDN & FDA & MM & Ca & P & EE \\
\hline Dezembro & 20,25 & 10,48 & 55,23 & 72,52 & 34,12 & 5,14 & 0,59 & 0,33 & 1,56 \\
Janeiro & 21,75 & 10,14 & 57,63 & 73,11 & 37,52 & 6,14 & 0,57 & 0,34 & 2,25 \\
Fevereiro & 21,52 & 9,48 & 54,78 & 74,41 & 73,23 & 6,01 & 0,53 & 0,29 & 1,24 \\
Março & 24,52 & 10,14 & 58,42 & 74,29 & 36,29 & 5,29 & 0,55 & 0,31 & 2,29 \\
Abril & 25,15 & 9,52 & 59,32 & 76,52 & 35,59 & 6,45 & 0,55 & 0,33 & 2,43 \\
Junho & 40,21 & 7,02 & 55,75 & 70,20 & 40,41 & 5,77 & 0,50 & 0,30 & 2,40 \\
\hline
\end{tabular}

$\mathrm{MS}=$ matéria seca; $\mathrm{PB}=$ proteína bruta; $\mathrm{NDT}=$ nutrientes digestíveis totais; $\mathrm{FDN}=$ fibra em detergente neutro; $\mathrm{FDA}=$ fibra em detergente ácido; $\mathrm{MM}=$ matéria mineral; $\mathrm{Ca}=$ cálcio; $\mathrm{P}=$ fósforo; $\mathrm{EE}=$ extrato etéreo.

Os níveis de proteína bruta $(\mathrm{PB})$ e matéria mineral $(\mathrm{MM})$ também variaram durante o período avaliado. Nos meses de dezembro a abril, as pastagens apresentaram teores de PB entre 10,48\% e 9,48\%, e no mês de junho os níveis de PB apresentaram-se inferiores (Tabela 5). Isso pode ser explicado pelo avanço do ciclo fenológico e consequente amadurecimento das forrageiras, que tendem a diminuir sensivelmente seus níveis de PB e aumentar os níveis de FDN ${ }^{(38)}$. Essa diminuição nos valores de PB pode levar à ocorrência de decréscimos nas taxas de digestão e no consumo de forragem e, dessa forma, a uma consequente deficiência energética nos animais ${ }^{(19)}$.

A produção média de matéria seca, a taxa de crescimento da forragem e a taxa de lotação instantânea no período avaliado foram respectivamente de $1.231,13 \mathrm{~kg}, 35,28 \mathrm{~kg}$ de $\mathrm{MS} / \mathrm{ha} / \mathrm{dia}$ e 1,95 animal/ha/dia (Tabela 6). Observou-se que, apesar da taxa de lotação e da disponibilidade de capim nesse período, os animais não passaram por privação alimentar, visto que a produção de MS/ha apresentava-se satisfatória e em crescimento em função do período chuvoso.

Tabela 6: Produção média de forragem em kg/ha de matéria seca, no período experimental, taxa de crescimento e taxa de lotação obtidas em pastos com novilhas

\begin{tabular}{lccc}
\hline Meses & $\begin{array}{c}\text { Produção } \\
\text { (kg de MS/ha) }\end{array}$ & $\begin{array}{c}\text { Taxa de } \\
\text { crescimento (kg de } \\
\text { MS/ha/dia) }\end{array}$ & $\begin{array}{c}\text { Taxa lotação } \\
\text { (animal/ha/dia) }\end{array}$ \\
\hline Dezembro & 860,0 & 26,87 & 1,49 \\
Janeiro & 706,8 & 23,56 & 1,30 \\
Fevereiro & 723,0 & 24,10 & 1,33 \\
Março & 2121,9 & 70,73 & 3,92 \\
Abril & 1965,9 & 32,76 & 1,82 \\
Junho & 1009,2 & 33,64 & 1,86 \\
Média & 1231,1 & 35,28 & 1,95 \\
\hline
\end{tabular}




\section{Conclusão}

No período chuvoso subsequente à complementação proteica, as novilhas não complementadas na seca apresentaram, quando primíparas ou novilhas, desempenhos ponderais e reprodutivos similares ao das complementadas.

\section{Referências}

1.Detmann E, Paulino MF, Valadares Filho SC, Huhtanen P. Nutritional aspects applied to grazing cattle in the tropics: a review based on Brazilian results. Semina: Ciências Agrárias, 2014;35(4):2829-54.

2.Lazzarini, I., Detmann E, Paulino MF, Valadares Filho SC, Diniz RF, Oliveira FA, Silva PT, Reis WLS. Nutritional performance of cattle grazing on low-quality tropical forage supplemented with nitrogenous compounds and/or starch. R. Bras. Zootec., 2013;42(9):664-74.

3.Reis RA, Ruggieri AC, Oliveira A A, Azenha MV, Casagrande DR. Supplementation as a strategy for the production of the beef quality in tropical pastures. Rev. Bras. Saúde Prod. Anim., 2012;13(3):642-655.

4.McGregor, E M, Campbell, C P, Miller, SP, Purslow, PP, Mandell, I.B. Effect of nutritional regimen including limit feeding and breed on growth performance, carcass characteristics and meat quality in beef cattle. Can. J. Anim. Sci. , 2012;92(3):327-341.

5.Homem Junior AC, Silva Sobrinho AG, Yamamoto SM, Pinheiro RSB, Buzzulini C, Lima CSA. Ganho compensatório em cordeiras na fase de recria: desempenho e medidas biométricas. R. Bras. Zootec., 2007;36(1):111-19.

6.Lobato JFP, Zanotta Júnior RLD, Pereira Neto OA. Efeitos das Dietas Pré e Pós-Parto na Eficiência Reprodutiva de Vacas Primíparas de Corte. R. Bras. Zootec., 1998;27(5):857-862.

7.Vaz RZ, Restle J, Pacheco PS, Vaz FN, Pascoal LL, Vaz MB. Ganho de peso pré e pós-desmame no desempenho reprodutivo de novilhas de corte aos quatorze meses de idade. Ci. Anim. Bras., 2012;13(3):272281.

8.Cavalcanti Filho LFM, Santos MVF, Ferreira MA, Lira MA; Farias I, Ferreira LRC, Lucena JEC. Desempenho de novilhas em pastagem de Brachiaria decumbens após período de suplementação. Pesq. Agropec. Bras., 2004;39(12):1247-52.

9.Semmelmann CEN, Lobato JFP, Rocha MG. Efeito de sistemas de alimentação no ganho de peso e desempenho reprodutivo de novilhas Nelore acasaladas aos 17/18 meses. R. Bras. Zootec., 2001;33(3):83543.

10.Ferreira MCN; Miranda R; Figueiredo MA; Costa OM; Palhano HB. Impact of body condition on pregnancy rate of cows nellore under pasture in fixed time artificial insemination (tai) program. Semina: Ciências Agrárias, 2013;34(4):1861-1868.

11.Barbero LM, Cecato U, Lugão SMB, Gomes JAN, Limão VA Basso , KC. Forage production and morphological components of coastcross pasture mixed with peanut forage. R. Bras. Zootec.2009;38(5):788795.

12.Compêndio brasileiro de alimentação animal. 3 ed. São Paulo: Sindirações/ANFAR; Campinas: CBNA/ SDR/MA, 2009. 390p. 
13.Scanavez AL, Campos CC, Santos RM. Pregnancy and pregnancy loss rates in recipients of bovine embryos produced in vitro. Arq. Bras. Med. Vet. Zootec. 2013;65(3):722-28.

14.Guimarães GN, Camargo PO. Potencialidade do GPS de navegação garmin 12 xl utilizando um sistema de baixo custo. Eng. Agríc., 2014;34(2):300-310.

15.Abouheif M, Al-Owaimer A, Kraidees M, Metwally H, Shafey ; T. Effect of restricted feeding and realimentation on feed performance and carcass characteristics of growing lambs. R. Bras.

Zootec. 2013;42(2):95-101.

16.Bezerra LR, Gonzaga Neto S, Medeiros NA, Mariz TMA, Oliveira, RL, Cândido, EP, Silva AMA. Feed restriction followed by realimentation in prepubescent Zebu females. Trop. Anim. Health Prod.

2013;45(5):1161-1169.

17.Gonzaga Neto S , Bezerra L R, Medeiros AN, Ferreira MA, Pimenta Filho EC, Cândido EP, Oliveira RL. Feed Restriction and Compensatory Growth in Guzerá Females. Asian-Aust. J. Anim. Sci. 2011;24(6):791799 .

18. Arrigoni MB, Vieira PF, Silveira AC, Furlan LR, Costa C, Chardulo LAL, Curi PR. Efeitos da restrição alimentar no desempenho de bovinos jovens confinados. Pesq. Agropec. Bras.,1998;33(6):987-92.

19.Euclides VPB, Euclides Filho K, Costa FP, Figueiredo, GR. Desempenho de novilhos F1s Angus-Nelore em pastagens de Brachiaria decumbens submetidos a diferentes regimes alimentares. R. Bras. Zootec., 2001;30(3):470-81.

20. Laureano, MMM, Boligon AA, Costa RB, Forni S, Severo JLP, Albuquerque LG. Estimativas de herdabilidade e tendências genéticas para características de crescimento e reprodutivas em bovinos da raça Nelore Arq. Bras. Med. Vet. Zootec., 2011;63(1):143-152.

21. Pereira E, Eler JP, Ferraz JBS. Correlação genética entre perímetro escrotal e algumas características reprodutivas na raça Nelore. R. Bras. Zootec., 2000;29(6):1676-83.

22.Vieira A, Lobato JFP, Corrêa ES, Torres Júnior RAA, Costa FP. Desenvolvimento e desempenho reprodutivo de novilhas Nelore criadas a pasto nos cerrados do Centro-Oeste brasileiro. R. Bras. Zootec., 2006;35(1):186-92.

23.Matos AS, Sena JSS, Marcondes CR, Bezerra LAF, Lôbo RB, Rorato PRN, Cucco DC, Araújo RO. Interação genótipo-ambiente em rebanhos Nelore da Amazônia Legal. Rev. Bras. Saúde Prod. Anim., 2013;14(3):599-608.

24.Tanaka ALR, Neves HHR, Oliveira JA, Carvalheiro R, Queiroz SA. Bioeconomic selection index for Nellore beef cattle females. Arch. zootec., 2012;61(236):537-548.

25.Dias LT, El Faro L, Albuquerque LG. Estimativas de Herdabilidade para Idade ao Primeiro Parto de Novilhas da Raça Nelore. R. Bras. Zootec., 2004;33(1):97-102.

26. Oliveira RL, Barbosa MAAF, Ladeira MM, Silva MMP, Ziviani AC, Bagaldo AR. Nutrição e manejo de bovinos de corte na fase de cria. Rev. Bras. Saúde Prod. Anim., 2006;7(1):57-86.

27.Rocha MG, Lobato JFP. Avaliação do desempenho reprodutivo de novilhas de corte primíparas aos dois anos de idade. R. Bras. Zootec., 2002;31(3):1388-95.

28.Pilau, A, Lobato, J FP. Desenvolvimento e desempenho reprodutivo de vacas primíparas aos 22/24 meses de idade. R. Bras. Zootec., 2009;38(4):728-36.

29.Soca P, Carriquiry M, Claramunt M, Ruprechter G, Meikle A. Metabolic and endocrine profiles of primiparous beef cows grazing native grassland. 2. Effects of body condition score at calving, type of 
suckling restriction and flushing on plasmatic and productive parameters. Animal Production Science., 2013;54(7):862-868.

30.Mulliniks J T, Cox SH, Kemp ME, Endecott RL, Waterman RC, VanLeeuwen DM, Petersen MK. Relationship between body condition score at calving and reproductive performance in young postpartum cows grazing native range. J. Anim. Sci., 2012;90(8):2811-17.

31.Freetly HC, Ferrell CL, Jenkins TG. Nutritionally altering weight gain patterns of pregnant heifers and young cows changes the time that feed resources are offered without any differences in productions. J. Anim. Sci., 2005;83(4):916-26.

32.Freetly HC, Ferrell CL, Jenkins TG. Timing of realimentation of mature cows that were feed - restricted during pregnancy influences calf birth weights and growth rates. J. Anim. Sci., 2000;78(11):2790-96.

33.Freneau GE, Silva JCC, Borjas ALR, Amorim C. Estudo de medidas corporais, peso vivo e condição corporal de fêmeas da raça Nelore Bos taurus indicus ao longo de doze meses. Ci. Anim. Bras., 2008;9(1):76-85.

34.Cordova IFM; Ciffoni EMG. Correlação entre a taxa de prenhez, idade, peso, medidas lineares e escore corporal, em novilhas Nelore de 13 a 24 meses, na região norte do Mato Grosso - Brasil. Cadernos de PósGraduação da FAZU, Uberaba. 2010; 7: 172-76. Disponível em: 〈http://www.fazu.br/ojs/index.php/posfazu/article/viewFile/313/219>. Acesso em junho 2012.

35.Souza JC, Perotto D, Abrahão JJ, Freitas JA, Ferraz Filho PB, Weaber RL, Lamberson WR. Estimativa das distâncias genéticas e componentes principais em bovinos de corte no Brasil. Arch. Zootec., 2010;59(228):479-485.

36.Boligon AA, Albuquerque LG, Mercadante MZ, Lôbo RB. Herdabilidades e correlações entre pesos do nascimento à idade adulta em rebanhos da raça Nelore. R. Bras. Zootec. 2009;38(12):2320-26.

37.Fujita AS, Weiss RR Rossi Junior P, Kozicki LE, Greselle FVN, Bertol MAF. Taxa de gestação em novilhas nelore sincronizadas para IATF e inseminadas com sêmen resfriado e congelado. Archives of Veterinary Science., 2013;18(3):13-21.

38.Velásquez PAT, Berchielli TT, Reis RA, Rivera AR, Dian PHM, Teixeira IAMA. Composição química, fracionamento de carboidratos e proteínas e digestibilidade in vitro de forrageiras tropicais em diferentes idades de corte. R. Bras. Zootec. 2010;39(6):1206-1213. 